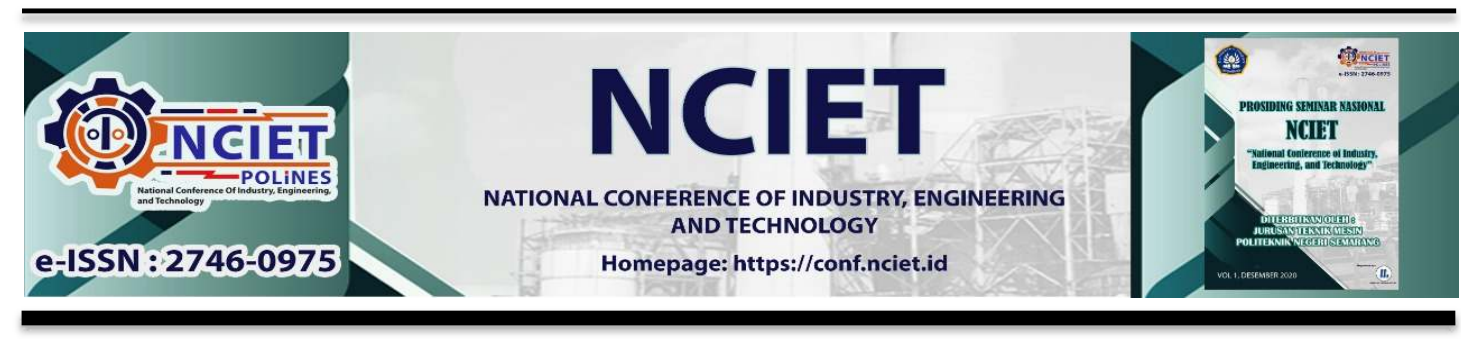

Prosiding Seminar Nasional NCIET Vol.1 (2020) B430-B439

$1^{\text {st }}$ National Conference of Industry, Engineering and Technology 2020,

Semarang, Indonesia.

\title{
PENGUJIAN SENSOR HMC5883L UNTUK PURWARUPA ROBOT BERODA
}

\section{Albertus Agung Dananto Setyawan ${ }^{1 *}$, Qoriatul Fitriyah², Berto Yusuf Nugroho ${ }^{3}$}

\author{
${ }^{1}$ Teknologi Rekayasa Mekatronika, Politeknik Industri ATMI \\ Jl. Kampus Hijau no. 3 Jababeka Education Park, Bekasi, 17530 \\ ${ }^{2}$ Teknik Elektro, Politeknik Negeri Batam \\ Jalan A. Yani, Batam, 29461 \\ ${ }^{3}$ Pemeliharaan Kendaraan Ringan, Akademi Komunitas Negeri Pacitan \\ Jl. Walanda Maramis No 4, Sidoharjo, Pacitan, 63514 \\ *E-mail: danan@polinatmi.ac.id
}

\begin{abstract}
Abstrak
Salah satu hal penting dalam sistem kendali di dalam purwarupa robot beroda adalah sistem navigasi. Pengujian sensor magnetormeter HMC5883L dilakukan untuk mengetahui kemampuan sensor tersebut ketika digunakan sebagai salah satu bagian navigasi pada purwarupa robot beroda. Pengujian dilakukan dengan membaca hasil keluaran sensor tersebut dengan menggunakan mikrokontroler yang telah diprogram. Dari hasil pengujian awal tersebut, sensor kompas lalu diaplikasikan pada purwarupa robot beroda. Robot diprogram untuk melakukan kalibrasi, dan setelah kalibrasi dilanjutkan dengan menggerakkan robot ke arah utara. Posisi hadap robot lalu dibandingkan dengan aplikasi kompas yang terdapat pada telepon genggam. Berdasarakan hasil percobaan tersebut, disimpulkan bahwa sensor magnetometer HMC5883L dapat digunakan dalam purwarupa robot beroda.
\end{abstract}

Kata Kunci: HMC5883L; sensor kompas; robot beroda; navigasi; magnetometer

\section{PENDAHULUAN}

Kendaraan pilot otomatis (autopilot vehicle) saat ini menjadi salah satu hal yang banyak diperbincangkan meskipun sebenarnya teknologi tersebut sudah dikembangkan beberapa tahun terakhir. Teknologi ini menjadi semakin dilirik setelah Tesla mengeluarkan produknya berupa mobil listrik yang dilengkapi dengan mode pilot otomatis. Kendaraan dengan sistem pilot otomatis pada prinsipnya adalah kendaraan yang dapat bergerak secara otomatis tanpa campur tangan operator. Kendaraan tersebut bergerak dengan memanfaatkan sensor-sensor yang terpasang baik di dalam maupun di luar kendaraan untuk mengenali kondisi lingkungan disekitarnya $[3,6]$.

Prinsip pada sistem kendaraan dengan pilot otomatis tersebut dapat diadopsi untuk digunakan pada kendaraan dan sistem yang lebih sederhana. Tujuan utama dibuatnya paper 
ini adalah sebagai percobaan awal untuk membuat sebuah robot beroda dengan sistem pilot otomatis. Robot tersebut kedepannya dapat digunakan untuk berbagai tujuan antara lain untuk robot pemotong rumput, robot pembawa barang, dan sistem lain yang membutuhkan sistem pilot otomatis.

Untuk sistem pergerakan robot dibutuhkan sensor yang tepat untuk mendukung navigasi robot yang sesuai dengan tujuan yang ditentukan. Semakin banyak jenis sensor yang digunakan, dapat membentuk sistem kendali yang semakin baik $[3,6]$. Selain sensor yang digunakan sebagai pengindera, juga dibutuhkan perlengkapan lain yaitu sumber tegangan, kontroler dan aktuator.

\section{Magnetometer Sensor (Sensor Kompas)}

Kompas sudah dijadikan sebagai pedoman untuk menentukan arah sejak jaman dahulu. Magnet yang ada di dalam kompas akan bereaksi terhadap medan magnet bumi. Prinsip yang sama digunakan pula dalam sensor kompas. Medan magnet bumi memiliki 3 dimensi sumbu dengan intensitas sebesar 0.5-0.6 Gauss. Sensor magnetik sendiri terdapat beberapa macam, antara lain: resosnant sensor, fluxgate sensor, dan hall sensor [5].

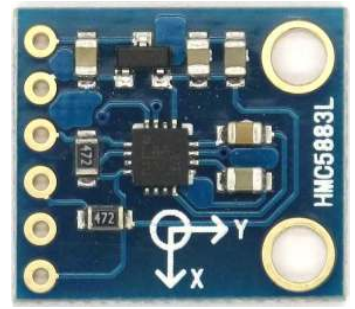

Gambar 1. Modul Sensor HMC5883L

Sumber: https://components101.com/ics/hmc58831-magnetometer-module

Sensor kompas yang digunakan dalam proyek ini adalah sensor dengan seri HMC5883L yang merupakan keluaran dari Honeyell. Sensor ini dapat bekerja dengan rentang tegangan 3-6 volt, dengan pembacaan ADC hingga 12bit. Rentang pembacaan densitas fluks magnetic sensor ini berada pada -8 sampai +8 Gauss. Protokol komunikasi yang digunakan adalah I2C sehingga dapat dihubungkan, dan dibaca hasil pengolahan sensor dengan menggunakan mikrokontroler.

\section{Mikrokontroler Arduino Mega 2560}

Untuk dapat membaca keluaran dari sensor kompas dan mengolah nilai yang dihasilkan supaya dapat digunakan untuk menggerakkan actuator, dibutuhkan komponen pemroses 
yaitu mikrokontroler. Mikrokontroler akan bertindak seperti otak pada manusia yang dapat memproses sinyal-sinyal yang masuk dan mengolahnya, melalui program yang sudah dimasukkan kedalamnya. Mikrokontroler yang akan digunakan adalah mikrokontroler ATMEGA 2560 yang telah tertanam pada sirkuit Arduino Mega.

Arduino Mega 2560 dipilih karena fasilitasnya sesuai dengan kebutuhan proyek ini. Mikrokontroler ini memiliki kaki input dan output sebanyak 54 kaki, dimana 15 diantaranya dapat digunakan untuk mode PWM. Mode PWM ini nanti akan digunakan untuk mengendalikan motor DC dengan perubahan kecepatan. Selain itu, mikrokontroler ini telah dilengkapi protocol komunikasi I2C sehingga dapat digunakan untuk membaca sensor kompas HMC5883L.

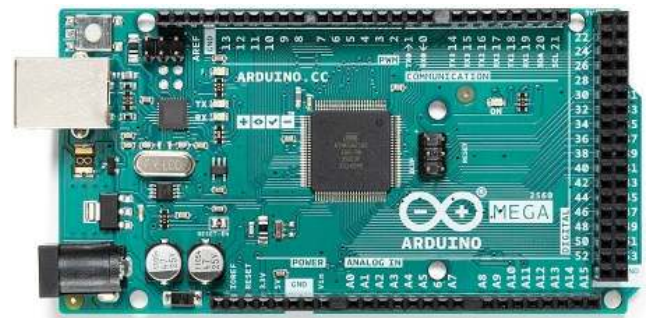

Gambar 2. Arduino Mega 2560

Sumber: https://store.arduino.cc/usa/mega-2560-r3

\section{Motor DC}

Aktuator yang digunakan dalam purwarupa ini adalah motor DC. Motor yang digunakan adalah motor DC dengan gearbox yang digunakan sebagai penggerak utama robot, dan motor servo yang akan digunakan untuk kemudi robot. Motor DC dengan gearbox akan dicatu dengan tegangan hingga maksimal 9 volt. Pengendaliannya dilakukan melalui rangkaian driver dengan IC L293D yang diatur dengan sinyal PWM untuk dapat mengubah kecepatan motor. Motor DC gearbox yang digunakan adalah motor bekas dari mainan remote control.

Motor servo yang digunakan sebagai kemudi merupakan motor servo berukuran kecil dengan seri SG90. Motor ini akan digerakkan secara langsung dari mikrokontroler dengan menggunakan logika digital. Motor ini memiliki rentang putar $180^{\circ}$ dan torsi maksimal $2.5 \mathrm{~kg} / \mathrm{cm}$ yang cocok untuk mengendalikan kemudi. 


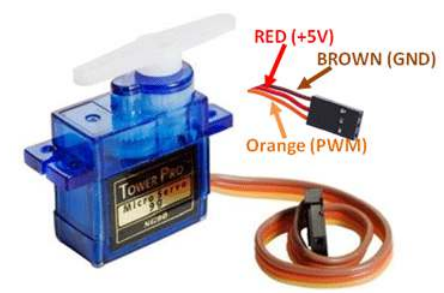

Gambar 3. Motor Servo SG90

Sumber: https://components101.com/servo-motor-basics-pinout-datasheet

\section{METODE PENELITIAN}

Pengujian yang dilakukan dalam purwarupa ini mencakup dua proses. Proses yang pertama adalah proses pembacaan nilai keluaran pada sensor,sedangkan proses kedua adalah pengaplikasian sensor pada purwarupa.

\section{Pembacaan Keluaran Sensor Kompas}

Proses pembacaan ini menggunakan sensor kompas yang dihubungkan langsung ke arduino, dan hasil pembacaan ditampilkan langsung melalui serial monitor pada arduino IDE. Langkah pembacaan dilakukan dengan meletakkan sensor kompas pada papan yang telah diberi tanda anak panah untuk menyatakan arah depan sensor. Selanjutnya papan sensor diletakkan diatas gambar yang berisi 4 garis dengan label sudut $0^{\circ}, 90^{\circ}, 180^{\circ}$, dan $270^{\circ}$ sebagai representasi dari arah utara, barat, selatan, dan timur.

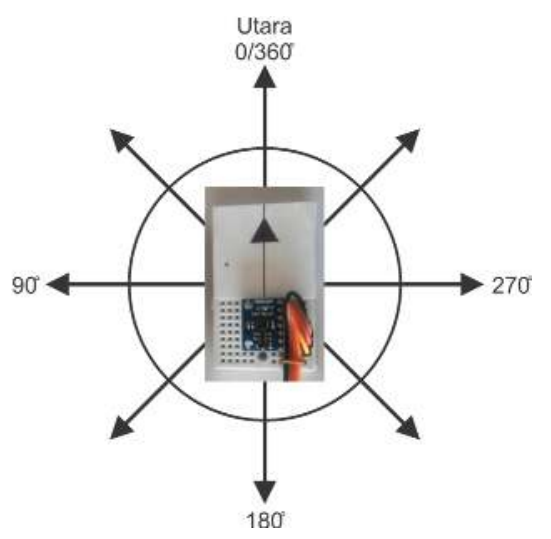

Gambar 4. Sarana Pembacaan Sensor Kompas

Langkah yang dilakukan pertama adalah menempatkan posisi papan sensor pada sudut $0^{\circ}$, lalu memposisikan gambar bersama papan sensor hingga sensor menghasilkan nilai 0 . Setelah itu gambar diatur supaya tidak bisa bergerak-gerak. Nilai yang tertampil saat menghadap ke $0^{\circ}$ dicatat, lalu papan sensor diputar ke sudut $90^{\circ}$, dan dibaca kembali hasilnya. Proses yang sama dilakukan untuk sudut $180^{\circ}$, dan $270^{\circ}$. Setelah itu papan sensor 
diputar lagi sampai proses di atas berulang sebanyak 3x. Percobaan di atas dilakukan untuk menguji akurasi dan kepresisian dari sensor tersebut.

\section{Pengaplikasian Sensor pada Purwarupa}

Langkah selanjutnya yang dilakukan untuk menguji hasil keluaran dari sensor kompas adalah dengan memasangkannya pada purwarupa. Purwarupa robot beroda dibuat dengan menggunakan mainan remote control bekas yang telah dimodifikasi. Motor DC yang digunakan pada roda belakang merupakan motor bawaan dari purwarupa tersebut. Kendali pada roda depan dimodifikasi dengan ditambahkan motor servo mini (lingkaran kuning pada Gambar 5). Sensor kompas diletakkan secara paralel, dan sehadap dengan robot. Untuk menghindarkan sensor dari gangguan medan magnet yang ditimbulkan oleh motor, maka sensor diletakkan pada sebuah tiang (lingkaran merah pada Gambar 5).

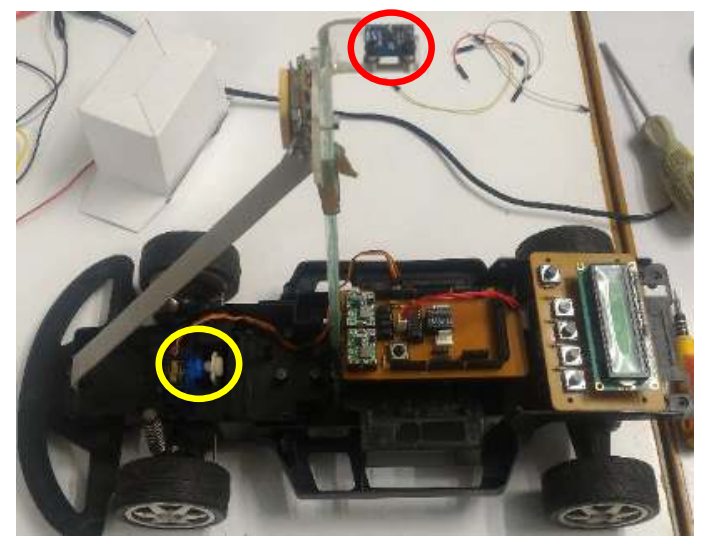

Gambar 5. Purwarupa Robot Beroda

Ada pun skema rangkaian elektrik yang digunakan pada purwarupa adalah sebagai berikut:

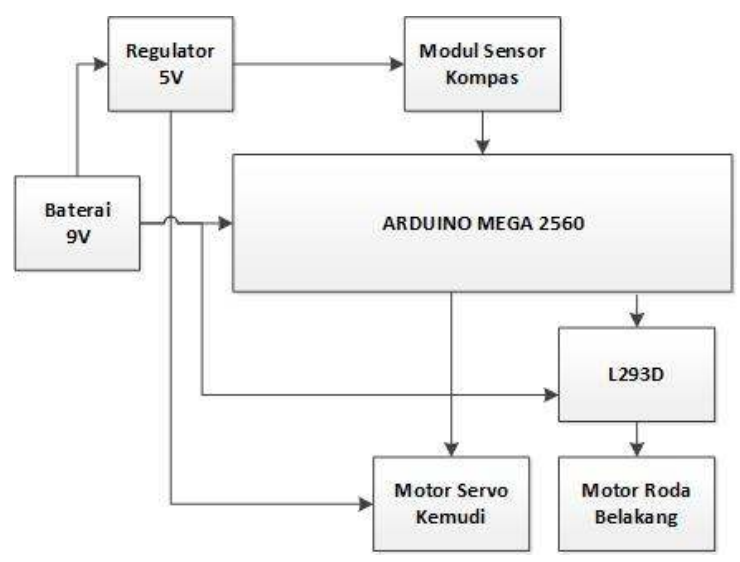

Gambar 6. Skema Rangkaian Elektrik 
Motor DC yang digunakan memiliki nilai catu daya sebesar 9V. Untuk bisa mengendalikan kecepatan pada motor, maka digunakan IC L293D sebagai driver sehingga memungkinkan kendali PWM dari mikrokontroler yang hanya mengeluarkan tegangan sebesar maksimal 5V. Modul sensor kompas terhubung secara langsung dengan mikrokontroler melalui protokol komunikasi I2C.

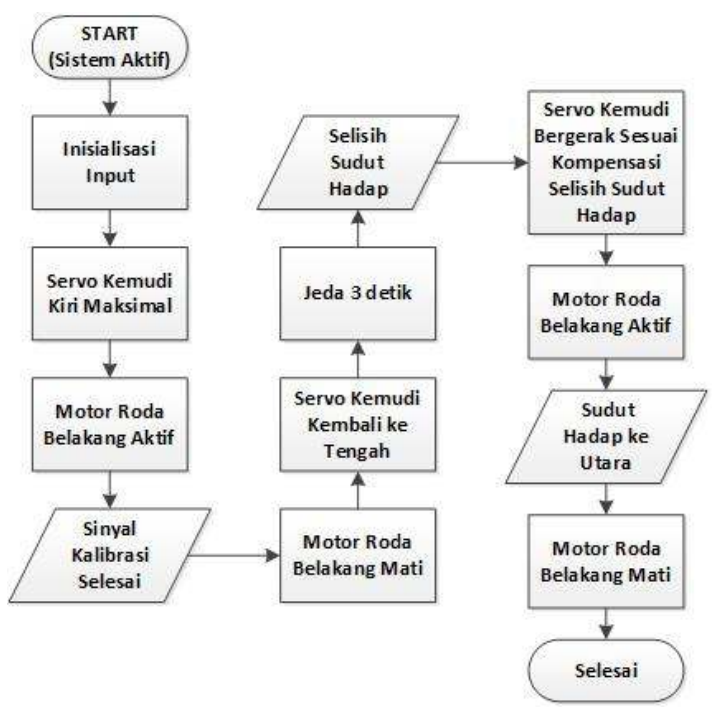

Gambar 7. Alur Pengujian Sensor pada Purwarupa

Langkah pengujian sensor kompas pada purwarupa seperti tertampil pada Gambar 7. Ketika sensor sistem dinyalakan, mikrokontroler akan melakukan insialisasi pada perangkat yang terhubung dengannya. Setelah itu proses akan masuk pada mode kalibrasi kompas yaitu dengan memerintahkan robot untuk berputar berlawanan arah jarum jam selama sekitar 3 menit. Apabila proses kalibrasi telah selesai, robot akan berhenti sejenak untuk membaca pengkinian data pada pembacaan sensor kompas. Jika arah hadap robot belum pada arah utara, maka servo kemudi akan bergerak untuk mengkompensasi arah hadap robot terhadap utara, disertai dengan roda belakang yang bergerak. Selanjutnya, jika sesudah robot bergerak telah mencapai arah utara, maka robot akan berhenti. Setelah itu, arah hadap robot akan dibandingkan secara visual dengan aplikasi kompas yang telah tertanam pada telepon genggam untuk mengecek seberapa besar penyimpangan yang terjadi pada kondisi akhir robot. 


\section{HASIL DAN PEMBAHASAN}

\section{Hasil Pembacaan Keluaran Sensor Kompas}

Setelah dilakukan proses pembacaan sensor pada sudut $0^{\circ}, 90^{\circ}, 180^{\circ}$, dan $270^{\circ}$ selesai dilakukan sebanyak 3x, didapatkan data sebagai berikut :

Tabel 1. Hasil Pembacaan Keluaran Sensor Kompas

\begin{tabular}{|l|l|l|l|l|}
\hline & $\mathbf{0}^{\mathbf{0}}$ & $\mathbf{9 0}^{\mathbf{0}}$ & $\mathbf{1 8 0}^{\mathbf{0}}$ & $\mathbf{2 7 0}^{\mathbf{0}}$ \\
\hline Uji 1 & $1^{\mathbf{0}}$ & $90^{\mathbf{0}}$ & $180^{\mathbf{0}}$ & $270^{\mathbf{0}}$ \\
\hline Uji 2 & $0^{\mathbf{0}}$ & $89^{\mathbf{0}}$ & $178^{\mathbf{0}}$ & $270^{\mathbf{0}}$ \\
\hline Uji 3 & $0^{\mathbf{0}}$ & $90^{\mathbf{0}}$ & $180^{\mathbf{0}}$ & $268^{\mathbf{0}}$ \\
\hline
\end{tabular}

Dari data yang tercantum pada Tabel 1, dapat dilihat bahwa sensor kompas ini memiliki nilai toleransi pembacaan sudut sebesar $1^{0}-2^{0}$. Dengan nilai toleransi yang kecil tersebut, menjadikan sensor ini cocok untuk digunakan sebagai navigasi robot beroda.

\section{Hasil Pengaplikasian Sensor pada Purwarupa}

Setelah mendapatkan hasil tingkat akurasi sensor sebesar $1^{0}-2^{0}$, maka langkah berikutnya adalah memasangkan sensor pada purwarupa robot beroda. Sebelum menguji coba sensor pada robot, langkah awal yang dilakukan adalah melakukan uji coba PWM pada mikrokontrol apakah dapat mengatur kecepatan motor roda belakang atau tidak. Pada uji coba ini, nilai tegangan yang diberikan pada motor roda belakang adalah separuh dari catu maksimalnya yaitu sebesar 4.5 volt. Jika nilai maksimal motor adalah 9 volt pada duty cycle 100\%, maka untuk mendapatkan nilai keluaran 4.5 volt pada L293D perlu diatur nilai duty cycle PWM sebesar 50\%.

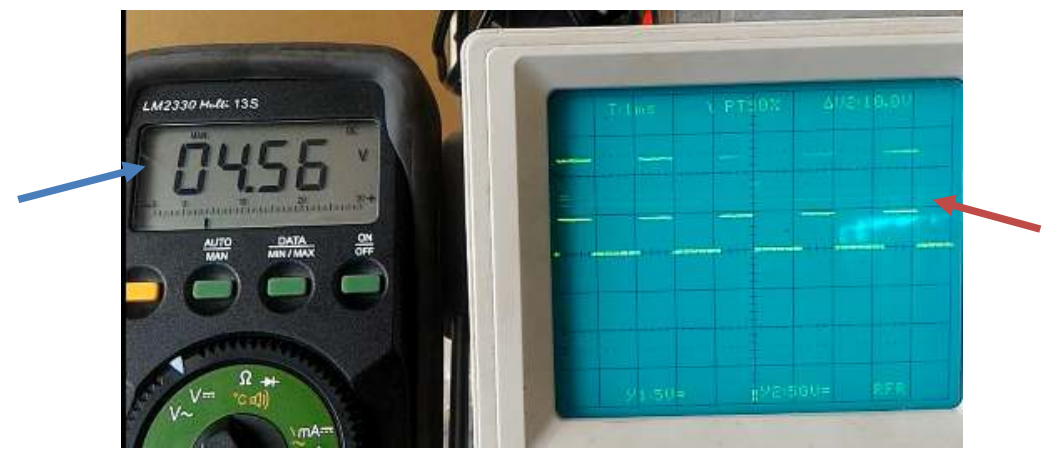

Gambar 8. Hasil Uji L293D

Pada Gambar 8 ditunjukkan bahwa pada saat nilai PWM diatur pada kisaran 50\% (panah merah, nilai tegangan yang terukur pada motor adalah pada kisaran 4.5 volt. 


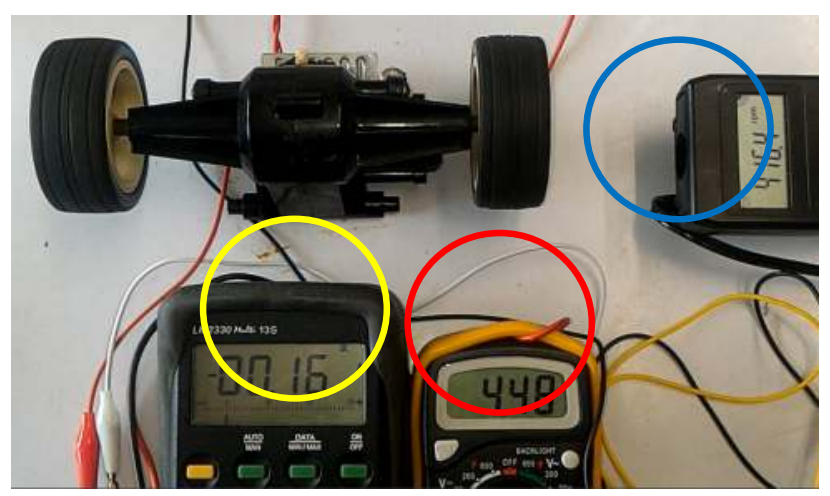

Gambar 9. Hasil Uji Arus dan Kecepatan Putaran Motor

Sedangkan pada Gambar 9 menunjukkan bahwa pada kondisi tegangan motor di kisaran 4.5 volt (lingkaran merah), ternyata arus listrik yang digunakan oleh motor sebesar 0.16 Ampere (lingkatan kuning) dan kecepatan putarnya sekitar 416 rpm (lingkaran biru). Dari beberapa hal di atas menunjukkan bahwa pengaturan PWM pada mikrokontroler dapat digunakan untuk mengatur nilai tegangan dan kecepatan pada motor.

Setelah sensor kompas diaplikasikan pada purwarupa, dan dilakukan proses pengujian seperti yang dijelaskan sebelumnya, robot dapat bergerak dan menghadap ke utara setelah proses kalibrasi selesai. Pengecekan arah hadap robot dilakukan dengan membandingkan arah hadap robot dengan aplikasi kompas digital pada telepon genggam seperti yang tertampil pada Gambar 10. Waktu yang dibutuhkan untuk bergerak menuju ke utara setelah proses kalibrasi tertampil pada Tabel 2. Hal tersebut menunjukkan bahwa untuk bisa mencapai arah utara pada kecepatan robot di kisaran 416 rpm membutuhkan waktu yang relatif singkat yaitu dengan rata-rata sebesar 3.74 detik

Tabel 2. Waktu Tempuh Robot

\begin{tabular}{|l|c|}
\hline & Waktu (detik) \\
\hline Uji 1 & 3.8 \\
\hline Uji 2 & 3.6 \\
\hline Uji 3 & 3.9 \\
\hline Uji 4 & 3.8 \\
\hline Uji 5 & 3.6 \\
\hline Rata-rata & 3.74 \\
\hline
\end{tabular}




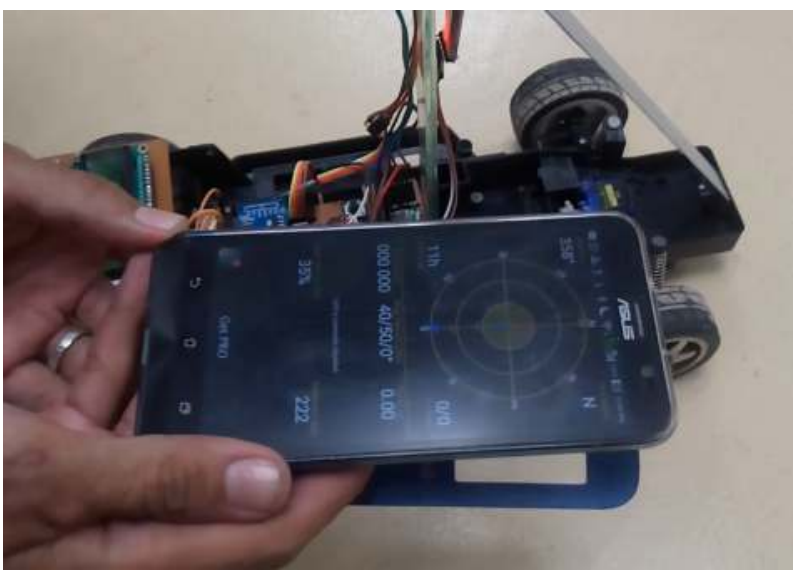

Gambar 10. Pengecekan Arah dengan Aplikasi Kompas Digital

\section{KESIMPULAN}

Dari beberapa rangkaian uji coba yang dilakukan, ditunjukkan bahwa sensor kompas tipe HMC5883L memiliki tingkat akurasi yang baik yaitu pada rentang $1^{0}-2^{\circ}$. Ketika sensor tersebut diaplikasikan pada purwarupa robot beroda juga memberikan hasil yang baik yaitu mampu mengarahkan robot untuk menghadap ke utara dengan waktu rata-rata 3.74 detik pada kecepatan $416 \mathrm{rpm}$.

Proses pengujian ini merupakan proses yang masih sangat awal untuk bisa membentuk sebuah robot beroda dengan sistem pilot otomatis. Akan baik jika proses pengujian ini dilakukan dengan variabel yang lebih kompleks dengan menerapkan beberapa kecepatan putaran motor karena pada penggunaannya nanti, robot beroda harus bisa menjalankan navigasi yang baik dan cepat dengan berbagai kemungkinan kecepatan. Juga masih perlu dilakukan pengujian dengan sistem navigasi yang lain seperti penggunaan GPS untuk luar ruangan, LIDAR, dan sensor-sensor pendukung yang lain.

\section{DAFTAR PUSTAKA}

[1].Arvin F., Samsudin,K., \& Nasseri, A.M. (2009). Design of a Differential-Drive Wheeled Robot Controller with Pulse-Width Modulation. Conference on Innovative Technologies in Intelligent Systems and Industrial Applications. 978-1-4244-28878.

[2].Boxall, J. (2013). Arduino Workshop A Hands-On Introduction with 65 Projects. San Fransisco: No Starch Press, Inc.

[3].Muhammad H.U.A, Umar S.K., \& Javaid I. Multipurpose Vehicle Tracking System Based on ARM CORTEX-M3 STM32, HMC5883L, MPU-6050, GSM and GPS. Journal of Traffic and Logistics Engineering, 4,7-12. 
[4].Scarpino,M. (2016). Motors For Makers - A Guide to Steppers, Servos, and Other Electrical Machines. Indianapolis: Pearson Education.

[5]. Todaro,M.T., Sileo, L. and Vittorio, M.D. (2012). Magnetic Sensors - Principles and Applications. Croatia:Intech.

[6]. Yousef M.A. \& Haithem A.A. (2018). Wheeled Mobile Robot Obstacle Avoidance Using Compass and Ultrasonic. Universal Journal of Control and Automation, 6, 1318 